${ }^{4}$ Alexander CM, Lum SMC, Rhodes J, Boarman C, Nokoloff JT, Kumar T. Rapid increase in both plasma fibronectin and serum triiodthyronine associated with treatment of diabetic ketoacidosis. J Clin Endocrinol Metab 1983;56:279-82.

5 Saba TM, Albert WH, Blumenstock FA, Evanega G, Stähler F, Cho E. Evaluation of a rapid immunoturbidimetric assay for opsonic fibronectin in surgical and trauma patients. J Lab Clin Med 1981;98:482-91.
${ }^{6}$ McCafferty MH, Lepow M, Saba MT, et al. Normal fibronectin levels as a function of age in the pediatric population. Pediatr Res 1983;17:482-5.

Correspondence to Dr U Muhar, Department of Paediatrics and Medicine, University of Vienna, Austria.

Received 27 March 1984

\title{
Gastric trichobezoar associated with transient pancreatitis
}

\author{
R N SHAWIS AND C M DOIG \\ Department of Paediatric Surgery, Booth Hall Children's Hospital, Manchester
}

SUMMARY A Pakistani girl presented with acute abdominal pain and raised serum amylase and alkaline phosphatase concentrations. She was found to have a gastric trichobezoar with a tail extending to the mid-ileum. The altered biochemical parameters returned to normal after surgical removal of the bezoar. Irritation of ampulla of Vater by the bezoar tail is believed to have caused transient pancreatitis.

Trichobezoar has been reported to cause a large number of complications ${ }^{1}$ but we believe this to be the first report of trichobezoar associated with pancreatitis.

\section{Case report}

A 15 year old Pakistani schoolgirl, resident in Britain for 12 years, presented as an emergency, complaining of severe colicky upper abdominal pain of 24 hours' duration. She had vomited bile stained fluid on two occasions during this period and had opened her bowels once noticing a streak of fresh blood in the stool. During the previous year she had had occasional upper abdominal pain and had not gained weight.

She was asthenic, pale, and ill looking; in pain and mildly dehydrated clinically. She had no fever, her pulse rate of $100 /$ minute, and her blood pressure was $120 / 70 \mathrm{~mm} \mathrm{Hg}$. There was a tender, mobile, firm mass in the epigastrium and right hypochondrium, with associated guarding. The bowel sounds were normal as was rectal examination. A full blood count showed only a mild, microcytic, normochromic anaemia. Her serum amylase concentration was raised at $2000 \mathrm{IU} / 1$ (normal up to $300 \mathrm{IU} / 1$ ) but urea and electrolyte concentrations were normal. Other biochemical abnormalities noted were a low serum albumin concentration of $28 \mathrm{~g} / 1$ and a raised serum alkaline phosphatase value of $800 \mathrm{IU} / \mathrm{l}$ (less than 600 IU/l is normal for our laboratory). Serum bilirubin and liver enzyme concentrations were normal. Plain abdominal radiography confirmed the presence of an upper abdominal mass surrounded by several loops of distended small bowel. An ultrasound scan showed the mass to be solid, making the diagnosis of a possible pancreatic pseudocyst unlikely. Other possible diagnoses were those of tumour or gastric bezoar. On subsequent questioning the patient admitted to trichophagia extending over a year. A barium meal (Figure) confirmed the diagnosis. Three days after admission the patient underwent laparotomy. A trichobezoar forming a complete cast of the stomach was found with a tail extending as far as the mid-ileum (Figure). The duodenal wall was hypertrophied and there was a solitary large chronic jejunal ulcer $6 \mathrm{~cm}$ from the duodenojejunal flexure. The pancreas, liver, gall bladder, and biliary tree were macroscopically normal.

The bezoar was removed completely through a single gastrotomy incision. The patient's serum amylase concentration 24 hours after surgery fell to 800 IU/l: thereafter it fell slowly and was $250 \mathrm{IU} / \mathrm{l}$ on discharge from hospital two weeks later. She had a psychiatric consultation before discharge. Five weeks later the patient was admitted to hospital for reassessment-full blood count and biochemical screen were normal.

\section{Discussion}

Trichobezoars are potentially lethal. The mortality of cases not operated on has been quoted as over $70 \%$, a figure which falls to under four per cent when surgical removal is undertaken. ${ }^{1}$ Death usually occurs secondary to gastric ulceration, perforation, and peritonitis from the bacterial contamination of the bezoar which always renders it noticeably foul and putrid. 

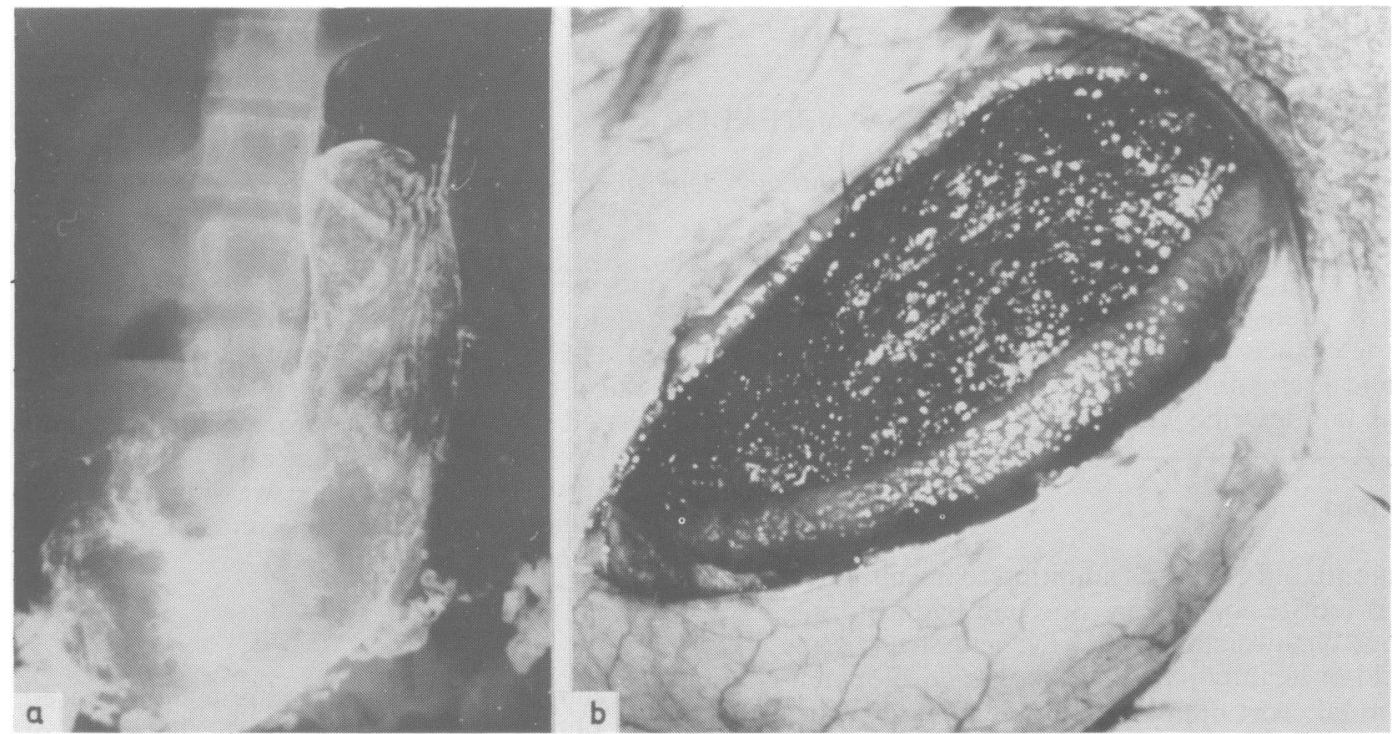

Figure (a) Barium meal showing the trichobezoar forming a complete cast in the stomach and (b) gastrotomy incision showing hair ball in the stomach.

The relation between gastric trichobezoar and its complications remains unclear. Constant irritation of the gastric mucosa by the stomach cast and the tail has been suggested as the cause of the gastric or intestinal ulceration ${ }^{1}$ and protein losing enteropathy. ${ }^{2}$ The associated low serum albumin concentration in this condition has, on occasion, caused obvious lower limb oedema. ${ }^{2}$ Gastric ulceration is far more common than small intestinal ulceration, occurring in about $10 \%$ of reported cases. ${ }^{1}$ Among rare complications which have been reported previously is the presence of multiple intussusceptions and small bowel ulceration. ${ }^{3}$

In our patient, irritation by the bezoar tail causing oedematous obstruction of the ampulla of Vater is suggested as a possible cause of the raised serum amylase and alkaline phosphatase concentrations. Supportive evidence is a report of obstructive jaundice due to trichobezoar. ${ }^{4}$ The fact that these altered biochemical parameters returned to normal after surgical removal of the bezoar suggests a causal relation. On the other hand, altered and increased bacterial content of the stomach and small bowel lumen may well be the cause of the reported association of steatorrhoea, ${ }^{2}$ of the microcytic anaemia due to malabsorption of iron, and indeed of the possible transient pancreatitis in the present case. Pancreatitis secondary to closed duodenal loop obstruction has been shown experimentally to be due to bacterial infection. ${ }^{5}$
In most cases the trichophagia is usually associated with psychiatric disturbance, and in our patient the period of trichophagia coincided with one of severe domestic and personal stress. Therefore, psychiatric consultation and a long follow up period are necessary as recurrence of trichophagia and eventually trichobezoar could occur. ${ }^{6}$

We thank Messrs A Jolly and A Bianchi under whose care this patient was admitted.

\section{References}

${ }^{1}$ De Bakey M, Ochsner A. Bezoars and concretions: comprehensive review of the literature with analysis of 303 collected cases and presentation of eight additional cases. Part I. Surgery 1938;4:934-63, and Part II Surgery 1939;5:132-60.

2 Hossenboccus A, Colin-Jones DG. Trichobezoar, gastric polyposis, protein-losing gastroenteropathy and steatorrhoea. Gut 1973;14:730-2.

${ }^{3}$ Gough MH. Multiple intussusception and intestinal perforation due to a bezoar. Br J Surg 1960;48:222-3.

${ }^{4}$ Schrieber H, Filestone H. Obstructive jaundice due to gastric trichobezoar. J Pediatr Surg 1976;11:103-4.

${ }^{5}$ Byrne JJ, Joison J. Bacterial regurgitation in experimental pancreatitis. Am J Surg 1964;107:317-20.

6 Booth IW, Harries JT, Glaser DR, et al. Multiple trichobezoars and laparotomies. J R Soc Med 1981;74:691-2.

Correspondence to $\mathrm{Dr} R \mathrm{R}$ Shawis, Department of Paediatric Surgery, Alder Hey Children's Hospital, Eaton Road, Liverpool 12.

Received 14 May 1984 